\title{
Natural Products for Material Protection: An Interesting and Efficacious Anticorrosive Property of Dry Arecanut Seed Extract at Electrode (Aluminum)-Electrolyte (Hydrochloric Acid) Interface
}

\author{
N. Raghavendra ${ }^{1} \cdot$ J. Ishwara Bhat ${ }^{1}$
}

Received: 4 June 2016/Revised: 18 June 2016/Accepted: 10 July 2016/Published online: 2 August 2016

(C) Springer International Publishing Switzerland 2016

\begin{abstract}
The inhibitory propensity of dry arecanut seed (DAS) extract was tested on aluminum metal in $0.5 \mathrm{M} \mathrm{HCl}$ media through weight loss, electrochemical, and probe techniques. Weight loss studies exhibited the anticorrosive effect of DAS extract constituents on the aluminum metal surface, protection efficiency, increased with an increase in the DAS extract concentration and subdued as the contact time lengthened. Inhibitive effect was afforded by adsorption of the DAS extract components which was approximated by proper Langmuir isotherm fit. The activation energy of aluminum corrosion and other thermodynamic functions were determined to corroborate the experimental findings and provide adequate insight into the aluminum corrosion inhibition mechanism. Inhibitive modality of the most potent inhibitor (DAS extract) was interpreted in detail through potentiodynamic polarization technique (Tafel plot). The impedance spectroscopy approach may well be able to foretell the formation of a persistent passive layer at the aluminum-acid interface that impedes the access of corrosive ions to the surface of aluminum. Surface analysis rationalized via atomic force microscopy technique manifested the absence of corrosion products and topographic modifications on the aluminum surface. The amorphous/crystalline nature of the inhibitor (DAS extract constituents) molecules adsorbed onto the aluminum surface was indicated by powder X-ray
\end{abstract}

Electronic supplementary material The online version of this article (doi:10.1007/s40735-016-0051-2) contains supplementary material, which is available to authorized users.

J. Ishwara Bhat

bhatij@yahoo.com

1 Department of Chemistry, Mangalore University, Mangalagangotri, Mangalore, Karnataka 574199, India diffraction technique. Protection efficiency values obtained by all techniques were complied with each other.

Graphical Abstract

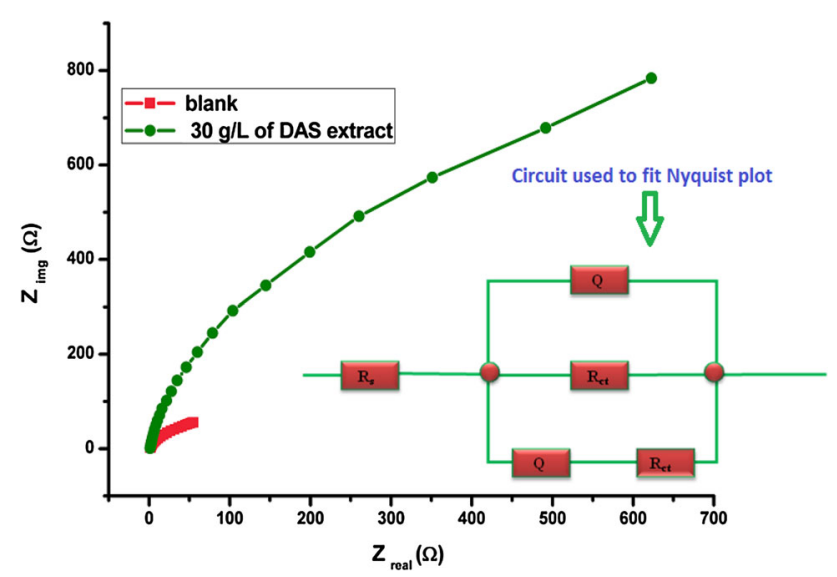

Keywords Dry arecanut seed · Langmuir isotherm fit . Aluminum corrosion - Passive layer · Protection efficiency

\section{Introduction}

Aluminum and its alloys find a tremendous spectrum of technological and many diversified industrial applications owing to its prominent properties such as high stiffness, lightweight, innocuousness, high thermal, and electrical conductivity [1-4]. Aluminum metal relies on the formation of a compact, adherent invisible oxide layer for its corrosion immunity in different environments [5]. However, this oxide layer is amphoteric and dissolves substantially when the aluminum metal is exposed to high concentration of $\mathrm{HCl}$ solutions for the duration of 
descaling, pickling, and electrochemical etching process [6]. Use of hydrochloric acid solutions in industries is unavoidable, which could lead to the dissolution of the aluminum metal in such hostile fluid environment [7]. Aluminum corrosion is an inevitable problem faced by almost all chemical industries can be considered as worst technical calamities of our period. As well from its direct costs in rupees, corrosion is a ubiquitous problem because its unquestionably contributes to the diminution of our natural properties. Therefore, the protection of aluminum and its alloy from hydrochloric acid solutions is of paramount importance for the growing industries. Hence, the studies of aluminum corrosion have invited the attention of technocrats and scientists to device ways to control the menace of corrosion. In efforts to mitigate aluminum corrosion, the main tactic is to separate the aluminum metal from aggressive environments. This can be achieved using various techniques such as cathodic protection, anodic protection, corrosion protection coating, inhibitors, lubrication, painting, and electroplating. Among the numerous methods used in combating corrosion problems, the use of inhibitors remains the most effective, practical, and viable method for corrosion abatement, especially in acidic media, which help enhance the lifespan of different materials [8-13]. Organic species particularly those bearing polar functionalities such as nitrogen, phosphorus, sulfur, oxygen and conjugated double bonds in their moiety are being applied as efficacious potential corrosion inhibitors for different metals. The inhibitory action of these species is usually through adsorption mechanism. These species are purported to form a tenacious adsorbed film on metal surfaces, ensuring that the metal is less prone to attack by corrosive agents in various aggressive environments [14-17]. Most of these organic species demonstrate superior anticorrosion action; however, they are highly toxic and expensive. Toxicity of the inhibitor (synthetic) can cause jeopardizing effects on living species, hence the use of these compounds has been restricted, which limits their application. To prevail over this lacunae, investigations is focused on the use of plant products as promising green anticorrosive agents as they are nontoxic, biodegradable, inexpensive, renewable sources of materials, and environmentally benign nature. Plant products are viewed as an extremely rich source of organic species that can be extracted through simple methods with low cost. Although a number of plant extracts (natural products) have been reported as effective green corrosion inhibitors, the majority of the significant plant products is not studied and discussed properly till date. Thus, enormous opportunities exist to find out novel and zero environmental impact inhibitors from this natural product. Therefore, the study of corrosion inhibition of metals by natural product extracts has aroused the curiosity among corrosion scientists to foster sustainable greenness to the environment [18-22].

Dry arecanut seed is one of such plant products significantly used in the treatment of leucoderma, Leprosy, cough, fits, worms, anemia, and obesity. In Ayurveda, arecanut was long considered to have medicinal properties. It is understood that different forms of Areca contain different types of chemical constituent with different concentrations. With maturation of seed, the concentration of alkaloids, polysaccharides, fiber, and fat contents increases, whereas polyphenols concentration decreases. Perusal of the literature shows that dry arecanut seed extract possessing rich sources of organic species, namely arecoline, arecaidine, guvacoline, guvacine, isoguvacine, and arecolidine (Fig. 1) [23-27]. Medicinal properties of this plant extracts are due to the presence of natural organic compounds bearing heteroatoms. Fortuitously, it has been reported that the acid corrosion of metals can be inhibited by compounds containing heteroatoms, and also no published information is available on the DAS extract as a green corrosion inhibitor for any aluminum metal in $0.5 \mathrm{M}$ $\mathrm{HCl}$ test solution. These specific points provoked us to find out the inhibiting action of the DAS extract on the aluminum metal surface in acidic atmosphere. Hence, the principal aim of present paper is to evaluate the anticorrosion behavior of DAS extract on aluminum surface in $0.5 \mathrm{M} \mathrm{HCl}$ solution using weight loss and electrochemical tests. Further, topographic modifications on the aluminum surface were visualized by AFM technique.

\section{Experimental Methodology}

\subsection{Materials Preparation}

Aluminum (Al-63400) metal having the chemical composition (in wt \%); $0.1 \% \mathrm{Cu}, 0.3-0.7 \% \mathrm{Si}, 0.4-0.9 \% \mathrm{Mg}, 0.3 \%$ Mn, $0.6 \% \mathrm{Fe}, 0.2 \% \mathrm{Cr}, 0.2 \% \mathrm{Zn}, 0.1 \%$ of Tl, or other grain refining elements and remainder $\mathrm{Al}$ [28] with dimensions of $2.4 \mathrm{~cm}$ length $\times 1.1 \mathrm{~cm}$ breadth $\times 0.2 \mathrm{~cm}$ thickness were utilized for weight loss, electrochemical, and AFM studies. For electrochemical and AFM studies, pieces were encapsulated in epoxy resin, so as to expose $1 \mathrm{~cm}^{2}$ surface area to the corrosive media. Prior to experiment, the specimens were well cleaned, and the exposed area was polished with fine grades of emery paper, degreased with absolute ethanol, dried in warm air, and stored in a desiccator.

\subsection{Extraction of Inhibitor}

Dried arecanuts were collected, chopped into small pieces, and ground well into fine powder in a mechanical grinder. 
Fig. 1 Main constituents of DAS extract, (i) arecoline, (ii) arecaidine, (iii) guvacine, (iv) guvacoline, (v) isoguvacine, (vi) arecolidine<smiles>COC(=O)C1=CCCN(C)C1</smiles>

(i)<smiles>COC(=O)C1=CCCNC1</smiles>

(iv)<smiles>CN1CCC=C(C(=O)O)C1</smiles>

(ii)<smiles>O=C(O)C1=CCNCC1</smiles>

(v)<smiles>O=C(O)C1=CCCNC1</smiles>

(iii)<smiles>COC1=C(OC)CN(C)C=C1</smiles>

(vi)
$80 \mathrm{~g}$ of above sample was extracted three times with $350 \mathrm{~mL}$ of double distilled water with the help of Soxhlet apparatus for $7 \mathrm{~h}$. After completion of extraction, the extract was cooled, fat content were removed using petroleum ether, and resulting solution was filtered through Whatman no.1 filter paper. The inhibitor with a concentration range of 5-30 g/L was prepared.

\subsection{Preparation of Corrosive Media}

The test solutions $(0.5 \mathrm{M} \mathrm{HCl})$ were prepared by dilution of an analytical grade hydrochloric acid obtained from Merck with doubly distilled water.

\subsection{Spectral Characterization [Fourier Transform Infrared (FT-IR) Spectrophotometer] of DAS Extract}

FT-IR spectrum was recorded and monitored by means of a prestige-21 FT-IR spectrophotometer with a wave number ranging from 4000 to $400 \mathrm{~cm}^{-1}$ for the DAS extract.

\subsection{Weight Loss Method}

In the weight loss studies, a previously weighted aluminum specimen was completely immersed in test solutions without and by means of different concentrations of DAS extract at $303-323 \mathrm{~K}$ in a thermostated water bath. After the effective duration, the electrodes (aluminum metal) were retrieved from the test solutions, and then carefully rinsed with bidistilled water, electrode surface was wiped with a new tissue paper, dried thoroughly, and weighed accurately using a digital balance.

The percentage protection efficiency $\left(\eta_{\mathrm{w}}\right)$ of the inhibitor at different DAS extract concentration was determined using the following formula

$\eta_{\mathrm{w}}=\frac{\left(W_{1}-W_{2}\right)}{W_{1}} \times 100$

where $W_{2}$ and $W_{1}$ are the loss of weight of electrode (aluminum) in the presence and absence of the plant extract, respectively.

The aluminum corrosion rate $\left(v_{\text {corr }}\right)$ in mils penetration per year (mpy) was calculated from weight loss values using the following relation [29]

$C_{\mathrm{R}}=\frac{534 \mathrm{~W}}{\mathrm{ATD}}$

where $C_{\mathrm{R}}$ is the corrosion rate of aluminum (mpy), $A$ is the area of aluminum specimen in square inches, $W$ is the weight loss of aluminum (mg), $T$ is the exposure time in hours, and $D$ is the density of aluminum specimen in grams per cubic $\mathrm{cm}$. Measurements were always repeated at least three times to get good reproducibility.

\subsection{Electrochemical Studies}

Corrosion studies through electrochemical measurements (both potentiodynamic polarization and $\mathrm{AC}$ impedance) were recorded by the $\mathrm{CHI} 660 \mathrm{C}$ workstation $(\mathrm{CH}$ instruments) at ambient temperature; for this purpose, a 
conventional three-electrode assembly was used. The reference electrode (saturated calomel electrode), working electrode (aluminum), and an auxiliary electrode (platinum) was used for the measurements. In the case of $\mathrm{AC}$ impedance spectroscopic and Tafel plot studies, prior to measurement, working electrode (aluminum) was immersed in the test solution for $35-40 \mathrm{~min}$ to attain a steady state open-circuit potential (OCP). Tafel curves were recorded by applying an electrode potential from the cathodic to anodic direction [open-circuit potential $(\mathrm{OCP}) \pm 200 \mathrm{mv}$ ] at a scan rate of $0.01 \mathrm{~V} \mathrm{~s}^{-1}$. All AC impedance measurements were carried out between the frequencies of 100,000 to $1 \mathrm{~Hz}$ using an $\mathrm{AC}$ signal with amplitude of $0.01 \mathrm{~V}$.

\subsection{Surface Examination}

The topology and nature of the interaction involving between the DAS extract and the aluminum metal surface were examined by atomic force microscopy (AFM, model: Nanosurf Easyscan2) technique. To capture the images of aluminum specimen, the sample was immersed in $0.5 \mathrm{M}$ $\mathrm{HCl}$ solution in the absence and presence of the DAS extract for $2 \mathrm{~h}$ at ambient temperature.

\subsection{Powder X-ray Diffraction Study}

To confirm the crystalline/amorphous property of the DAS extract on aluminum surface, it was subjected to powder X-ray diffraction analysis (Rigaku miniflex $600 \mathrm{~W}$ ). XRD pattern of the DAS extract on aluminum specimen after the 2-h exposure in an $0.5 \mathrm{M} \mathrm{HCl}$ medium was recorded.

The crystallite size (L) of crystalline phases in the examined solid (DAS extract) was based on X-ray diffraction line broadening and evaluated using Scherrer relation [30] as follows:

$L=\frac{B \lambda}{\beta \cos \theta}$,

where $L$ is the crystallite size of the phase, $\theta$ is the Bragg's angle, $\lambda$ is the wavelength of X-ray beam used, $B$ is the Scherre constant (0.95), and $\beta$ is the full-width half maximum (FWHM) of diffraction.

\section{Results and Discussion}

\subsection{Weight Loss Studies}

Corrosion rate measurement via weight loss (gravimtric measurement) method is probably the most widely used technique for inhibition assessment. The weight loss (gravimetric studies) method was used to optimize the concentrations of the inhibitor and will give a baseline to the electrochemical (Tafel plot and impedance study) techniques.

The corrosion rate $\left(v_{\text {corr }}\right)$ of aluminum metal and other corrosion functions were determined by weight loss test for different inhibitor concentrations at various immersion times $(1,2,3,4,5,10,11$, and $12 \mathrm{~h})$. The obtained parameters are provided in Tables 1 and 2. Figure 2 showed that the rate of corrosion of aluminum in severe condition was suppressed noticeably with increment in the inhibitor concentrations which corresponds to an increase in protection efficiency. The decreased corrosion rate with an increase in inhibitor concentrations is believed to be due to the adsorption DAS extract molecules on the aluminum metal/acid solution interface which effectively reduced the exposed surface area of the aluminum metals in acid solution. The higher protection efficiency values are acknowledged due to the higher adsorption of DAS extract molecules on aluminum surfaces.

It is also observed that rate of aluminum corrosion in acid solution enhanced with an increase in the test solution temperature is due to the instability of the tenacious barrier layer formed over the aluminum surface at higher temperatures. The temperature effect on the inhibited acidaluminum metal reaction is very complex, because many changes occur on the aluminum metal surface such as rapid etching and desorption of inhibitor, and the inhibitor (DAS extract) itself may undergo decomposition. The desorption weakness the aluminum-DAS extract molecules interaction resulting in a drop in protection efficiency [31, 32]. The influence of immersion time on protection efficiency is shown (Fig. 3). The protection efficiency decreased with an increase in exposure time till $10 \mathrm{~h}$ and later, there was no effect of immersion time on protection efficiency.

Activation parameters such as enthalpy of activation $\left(\Delta H^{*}\right)$, activation energy $\left(E_{\mathrm{a}}\right)$, and entropy of activation $\left(\Delta S^{*}\right)$ are required to understand the kinetics of the corrosion process.

To explore the apparent activation energy $\left(E_{\mathrm{a}}\right)$ of the metal corrosion process, the variation of corrosion rate of the metal with different solution temperature is to be studied.

The apparent activation energy $\left(E_{\mathrm{a}}\right)$ of metal (including aluminum) corrosion in acidic environments was calculated by $v_{\text {corr }}$ values from the Arrhenius equation [33]

$\ln v_{\text {corr }}=\ln \mathrm{A}-\frac{E_{\mathrm{a}}^{*}}{\mathrm{RT}}$,

where $T$ is the absolute temperature, $A$ is an Arrhenius pre exponential factor, $R$ is the gas constant, $v_{\text {corr }}$ is the corrosion rate, and $E_{\mathrm{a}}^{*}$ is the apparent activation energy.

The apparent activation energy $\left(E_{\mathrm{a}}\right)$ and Arrhenius preexponential factors at different inhibitor concentrations 
Table 1 Weight loss parameters for aluminum in $0.5 \mathrm{M} \mathrm{HCl}$ in the absence and presence of different concentrations of the inhibitor at $303 \mathrm{~K}$

\begin{tabular}{|c|c|c|c|c|}
\hline Time (hours) & Concentration $\left(\mathrm{g} \mathrm{L}^{-1}\right)$ & $\left(v_{\text {corr }}\right) \times 10^{-4}(\mathrm{mpy})$ & $\begin{array}{l}\text { Surface } \\
\text { coverage }(\theta)\end{array}$ & $\begin{array}{l}\text { Inhibition } \\
\text { efficiency }\left(\eta_{w}\right)\end{array}$ \\
\hline \multirow[t]{5}{*}{1} & Blank & 8.699 & & \\
\hline & 5 & 1.933 & 0.777 & 77.777 \\
\hline & 10 & 1.449 & 0.833 & 83.333 \\
\hline & 20 & 0.966 & 0.888 & 88.888 \\
\hline & 30 & 0.483 & 0.944 & 94.444 \\
\hline \multirow[t]{5}{*}{2} & Blank & 11.116 & & \\
\hline & 5 & 2.658 & 0.760 & 76.086 \\
\hline & 10 & 2.416 & 0.782 & 78.260 \\
\hline & 20 & 1.691 & 0.847 & 84.782 \\
\hline & 30 & 1.208 & 0.891 & 89.130 \\
\hline \multirow[t]{5}{*}{3} & Blank & 16.110 & & \\
\hline & 5 & 4.027 & 0.75 & 75 \\
\hline & 10 & 3.705 & 0.77 & 77 \\
\hline & 20 & 3.222 & 0.80 & 80 \\
\hline & 30 & 2.255 & 0.86 & 86 \\
\hline \multirow[t]{5}{*}{4} & Blank & 18.124 & & \\
\hline & 5 & 4.833 & 0.733 & 73.333 \\
\hline & 10 & 4.470 & 0.753 & 75.333 \\
\hline & 20 & 3.624 & 0.800 & 80.000 \\
\hline & 30 & 3.020 & 0.833 & 83.333 \\
\hline \multirow[t]{5}{*}{5} & Blank & 24.166 & & \\
\hline & 5 & 7.249 & 0.700 & 70.000 \\
\hline & 10 & 6.766 & 0.720 & 72.000 \\
\hline & 20 & 5.993 & 0.752 & 75.200 \\
\hline & 30 & 4.833 & 0.800 & 80.000 \\
\hline \multirow[t]{5}{*}{10} & Blank & 42.291 & & \\
\hline & 5 & 16.916 & 0.600 & 60.000 \\
\hline & 10 & 15.949 & 0.622 & 62.285 \\
\hline & 20 & 14.499 & 0.657 & 65.714 \\
\hline & 30 & 12.083 & 0.714 & 71.428 \\
\hline \multirow[t]{5}{*}{11} & Blank & 46.135 & & \\
\hline & 5 & 18.014 & 0.609 & 60.952 \\
\hline & 10 & 17.575 & 0.619 & 61.904 \\
\hline & 20 & 16.257 & 0.647 & 64.761 \\
\hline & 30 & 13.181 & 0.714 & 71.428 \\
\hline \multirow[t]{5}{*}{12} & Blank & 52.360 & & \\
\hline & 5 & 20.541 & 0.607 & 60.769 \\
\hline & 10 & 20.138 & 0.615 & 61.538 \\
\hline & 20 & 18.124 & 0.653 & 65.384 \\
\hline & 30 & 14.490 & 0.715 & 71.538 \\
\hline
\end{tabular}

were calculated from linear regression between $\ln v_{\text {corr }}$ versus 1/T as shown in Fig. 4, and calculated parameters are given in Table 3. It is inferred from the table that both $E_{\mathrm{a}}^{*}$ and $A$ values are higher in the presence of DAS extract compared to uninhibited system. This implies that the addition of inhibitor (DAS extract) hinders the aluminum metal dissolution in $0.5 \mathrm{M} \mathrm{HCl}$ medium by enhancing the energy barrier for the aluminum corrosion process. Moreover, with increases in the inhibitor concentration (DAS extract), the difficulty in the movement of $\mathrm{H}^{+}$ions further increases and hence the value of apparent activation energy for the corrosion reaction also increases [34]. Corrosion 
Table 2 Effect of temperature on the inhibition efficiency for aluminum in $0.5 \mathrm{M} \mathrm{HCl}$ solution at different concentrations of DAS extract with immersion time of $1 \mathrm{~h}$

\begin{tabular}{|c|c|c|c|c|}
\hline Temperature $(\mathrm{K})$ & Concentration $\left(\mathrm{g} \mathrm{L}^{-1}\right)$ & $\left(v_{\text {corr }}\right) \times 10^{-4}(\mathrm{mpy})$ & Surface coverage $(\theta)$ & Inhibition efficiency $\left(\eta_{w}\right)$ \\
\hline \multirow[t]{5}{*}{303} & Blank & 8.699 & & \\
\hline & 5 & 1.933 & 0.777 & 77.777 \\
\hline & 10 & 1.449 & 0.833 & 83.333 \\
\hline & 20 & 0.966 & 0.888 & 88.888 \\
\hline & 30 & 0.483 & 0.944 & 94.444 \\
\hline \multirow[t]{5}{*}{308} & Blank & 9.666 & & \\
\hline & 5 & 2.416 & 0.75 & 75.000 \\
\hline & 10 & 1.933 & 0.80 & 80.000 \\
\hline & 20 & 1.449 & 0.85 & 85.000 \\
\hline & 30 & 0.966 & 0.90 & 90.000 \\
\hline \multirow[t]{5}{*}{313} & Blank & 10.633 & & \\
\hline & 5 & 2.899 & 0.727 & 72.727 \\
\hline & 10 & 2.416 & 0.772 & 77.272 \\
\hline & 20 & 1.933 & 0.818 & 81.818 \\
\hline & 30 & 1.449 & 0.863 & 86.363 \\
\hline \multirow[t]{5}{*}{318} & Blank & 12.083 & & \\
\hline & 5 & 3.383 & 0.720 & 72.000 \\
\hline & 10 & 2.899 & 0.760 & 76.000 \\
\hline & 20 & 2.416 & 0.800 & 80.000 \\
\hline & 30 & 1.933 & 0.840 & 84.000 \\
\hline \multirow[t]{5}{*}{323} & Blank & 13.049 & & \\
\hline & 5 & 3.866 & 0.703 & 70.370 \\
\hline & 10 & 3.383 & 0.740 & 74.074 \\
\hline & 20 & 2.899 & 0.777 & 77.777 \\
\hline & 30 & 2.416 & 0.814 & 81.481 \\
\hline
\end{tabular}

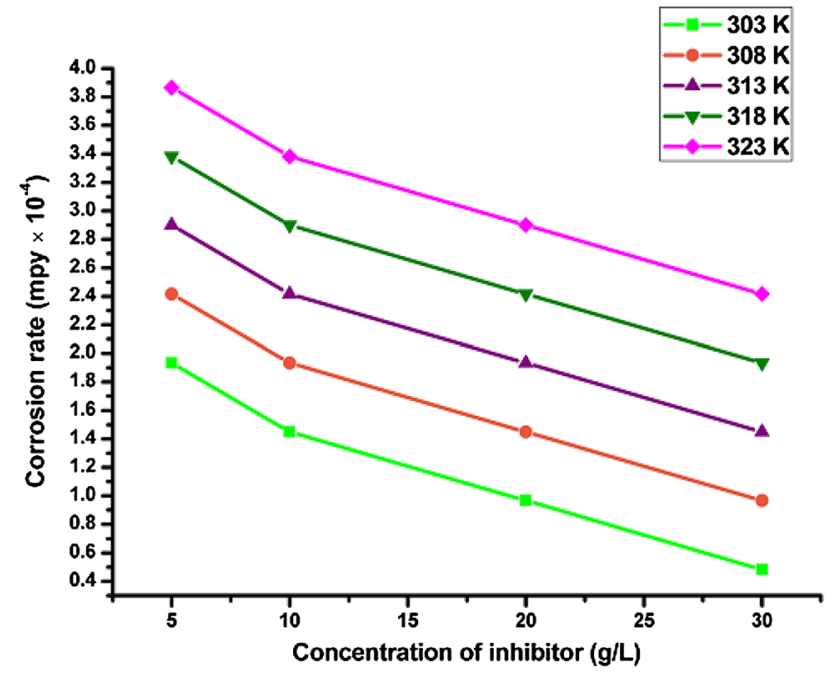

Fig. 2 Effect of DAS extracts concentration on the corrosion rate at different temperatures rate values obtained from weight loss studies at different temperature were used to calculate change in enthalpy $\left(\Delta H^{*}\right)$ and entropy of activation $\left(\Delta S^{*}\right)$ by the transition state equation given below [35]

$\ln \frac{v_{\text {corr }}}{T}=\left[\ln \frac{R}{\mathrm{Nh}}+\frac{\Delta S^{*}}{R}\right]-\frac{\Delta H^{*}}{\mathrm{RT}}$,

where $N$ is Avogadro's number, $v_{c o r r}$ is the corrosion rate, $R$ is the gas constant and $T$ is temperature, and $h$ is Planck's constant.

$\Delta H^{*}$ and $\Delta S^{*}$ values were calculated from the plot of $\ln$ $\left(v_{c o r r} / T\right)$ against 1000/T (Fig. 5) that gave straight line with a slope of $-\Delta H^{*} / R$ and intercept of $\ln v_{c o r r} / T$, and computed parameters are given in Table 3 .

The positive values of $\Delta H^{*}$ indicate the dissolution of aluminum in $0.5 \mathrm{M} \mathrm{HCl}$ system is an endothermic nature. $\Delta H^{*}$ value increases with an increase in the inhibitor (DAS extract) concentration suggests that the endothermic nature 


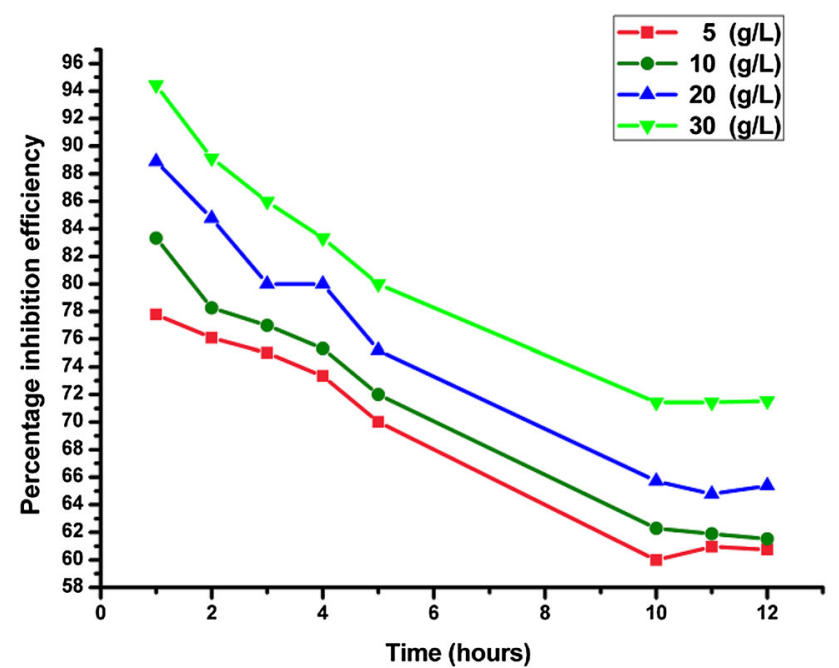

Fig. 3 Effect of immersed period on inhibition efficiency at different inhibitor concentration extract

has enhanced with increment in the DAS extract concentration. The active sites on the aluminum surface sites get blocked by the adsorbed molecules present in DAS extract and hence pose difficulty in the interaction of $\mathrm{H}^{+}$ions with active sites on the aluminum surface. $\Delta S^{*}$ is a measure of disorder in a system. The increase in the entropy of activation $\left(\Delta S^{*}\right)$ values in the presence of inhibitor showed that the activated complex during the rate-determining stage reflects dissociation instead of association, showing that a decrease in disorder takes place on shifting from reactants to the activated complex [36-39].

\subsection{Adsorption Isotherm}

Organic compounds are usually effective inhibitor components found in natural products. The efficiency of an

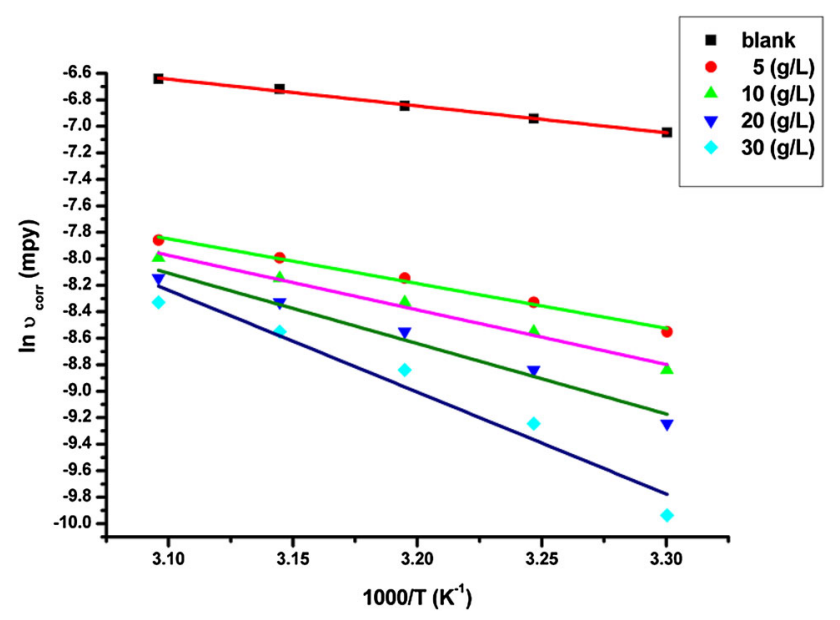

Fig. 4 Arrhenius plots for aluminum in $0.5 \mathrm{M} \mathrm{HCl}$ solution without and with DAS extract of different concentrations organic species as a successful corrosion inhibitor is mainly dependent on its ability to get adsorbed on the surface of the metal. Adsorption isotherm models can provide important clues to the nature of metal-inhibitor interaction. Attempts were made to find a good fit for DAS extract constituents adsorption on metal surface with various isotherms including Frumkin, kinetic thermodynamic model, Flory-huggins, Freundlisch, Temkin, and Langmuir adsorption model. In the present case, best results were obtained by Langmuir isotherm model (Fig. 6, plot of $C_{\text {inh }}$ $\mathrm{g} / \mathrm{L}$ against $\left.C_{\mathrm{inh}} / \theta \mathrm{g} / \mathrm{L}\right)$ with $R^{2}$ value $>0.997$.

According to this adsorption model, the surface coverage $(\theta)$ is related to the concentration of inhibitor by the following relation [40]

$\frac{C}{\theta}=\frac{1}{K_{\mathrm{ads}}}+C$,

where $K_{\text {ads }}$ is the equilibrium constant of adsorption process, $\theta$ is the degree of surface coverage, and $C$ is the concentration of inhibitor (plant extract). $K_{\text {ads }}$ values were determined from the intercepts of $C_{\mathrm{inh}} / \theta$ axis. The nature of interaction between the aluminum metal surface with the constituents of DAS extract was obtained using the free energy of adsorption values. The $K_{\text {ads }}$ is related to the free energy of adsorption ( $\Delta G_{\text {ads }}^{\circ}$ ) by the expression [41]

$\Delta G_{\text {ads }}^{\mathrm{o}}=-2.303 \mathrm{RT} \log \left(K_{\mathrm{ads}} C_{\mathrm{H}_{2} \mathrm{O}}\right)$,

where $T$ is the absolute temperature, $C_{\mathrm{H}_{2} \mathrm{O}}$ is the concentration of water in solution equals $1000 \mathrm{~g} / \mathrm{L}$ and $R$ is the gas constant.

Slope values from the plot of $\Delta G_{\text {ads }}^{\mathrm{o}}$ versus $1000 / \mathrm{T}$ was used to evaluate the adsorption enthalpy ( $\Delta H_{\mathrm{ads}}^{\mathrm{o}}$ ) as shown in Fig. 7. The following Gibbs-Helmholtz equation can be used to calculate the entropy of adsorption $\left(\Delta S_{\mathrm{ads}}^{\mathrm{o}}\right)$

$\Delta S_{\mathrm{ads}}^{0}=\frac{\left(\Delta H_{\mathrm{ads}}^{0}-\Delta \mathrm{G}_{\mathrm{ads}}^{0}\right)}{T}$,

and all parameters summarized in Table 4. From the table, it is observed that higher values of $K_{\text {ads }}$ indicates the better protection efficiency of a given inhibitor (DAS extract) and an effective electrostatic interaction between the double layer existing on the phase boundary and the adsorbed groups. It decreases with the rise in temperature possibly owing to the thermal agitation of constituents of the DAS extract, denoting that adsorbed DAS extract molecules are easily replaceable by the solvent molecule from the surface. The lower negative values of $\Delta G_{\text {ads }}^{\mathrm{o}}$ ensure the spontaneity of the adsorption process and stability of the adsorbed protective film formed over the aluminum metal surface. Generally, values of free energy up to $-20 \mathrm{~kJ} \mathrm{~mol}^{-1}$ associated with the electrostatic interactions existing in between corrosion inhibitor and the charged metal (including aluminum metal) surface (i.e., 
Table 3 Activation parameters

\begin{tabular}{llrll}
\hline Concentration $\left(\mathrm{g} \mathrm{L}^{-1}\right)$ & $\mathrm{Ea}^{*}\left(\mathrm{~kJ} \mathrm{~mol}^{-1}\right)$ & $\mathrm{A}\left(\mathrm{kJ} \mathrm{mol}^{-1}\right)$ & $\Delta H^{*}\left(\mathrm{~kJ} \mathrm{~mol}^{-1}\right)$ & $\Delta S^{*}\left(\mathrm{~J} \mathrm{~mol}^{-1} \mathrm{~K}^{-1}\right)$ \\
\hline Blank & 16.830 & 0.692 & 14.230 & -313.901 \\
5 & 28.084 & 13.773 & 25.483 & -289.036 \\
10 & 34.248 & 121.125 & 31.648 & -270.960 \\
20 & 44.194 & 4315.339 & 41.593 & -241.253 \\
30 & 63.926 & 5944755.736 & 61.325 & -181.159 \\
\hline
\end{tabular}

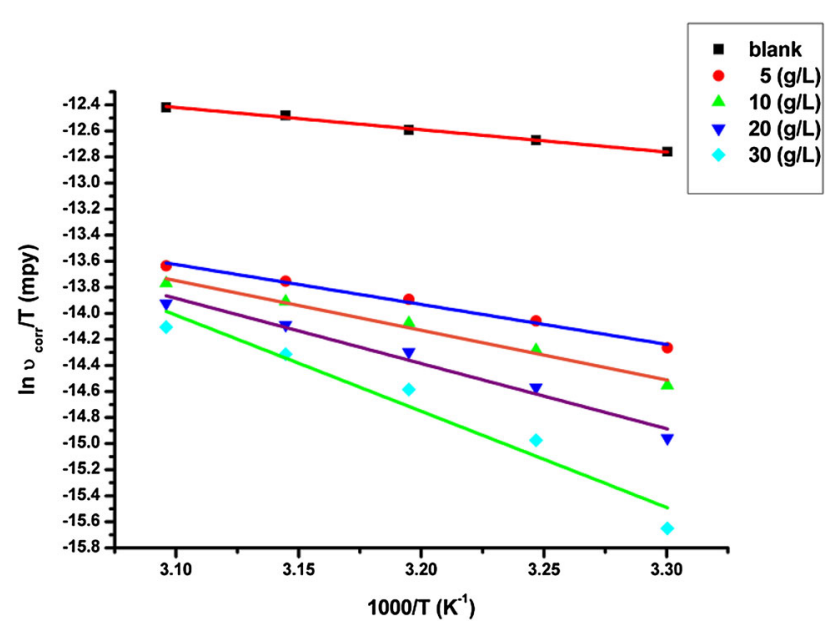

Fig. 5 Transition state plots

physisorption). In contrast, for the values around $-40 \mathrm{~kJ} \mathrm{~mol}^{-1}$ or smaller involve electron sharing or electron transfer from organic molecules to the metal (including aluminum metal) surface (i.e., chemisorptions). The $\Delta G_{\text {ads }}^{\mathrm{o}}$ values obtained in the present system lie between -33.472 and $-36.078 \mathrm{~kJ} / \mathrm{mol}$. It suggested that the adsorption mechanism of the DAS extract on aluminum surface in $0.5 \mathrm{M} \mathrm{HCl}$ solution was an intermediate range, which suggests a comprehensive adsorption (both physical and chemical adsorption) [42, 43]. The positive values of

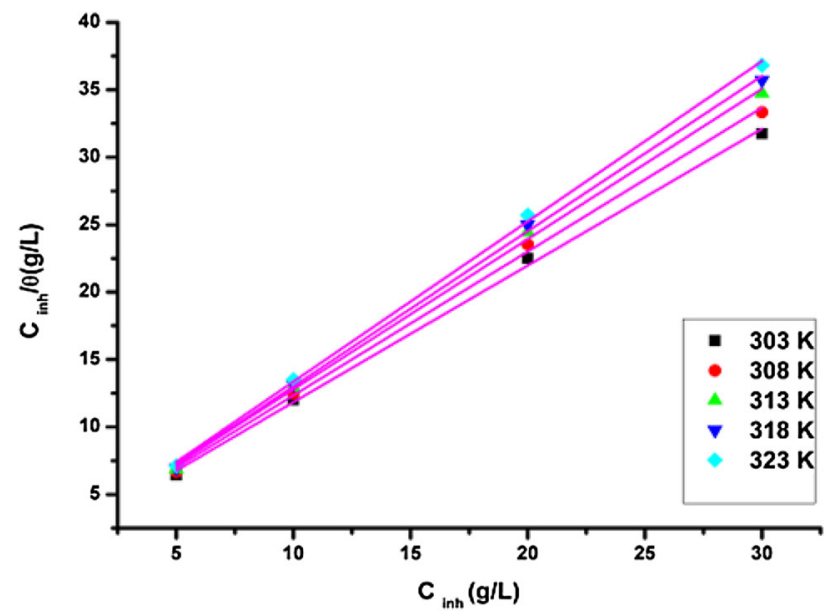

Fig. 6 Langmuir adsorption isotherms for aluminum in $0.5 \mathrm{M} \mathrm{HCl}$ without and with inhibitor of different concentrations enthalpy of adsorption $\left(\Delta \mathrm{H}_{\mathrm{ads}}^{\circ}\right)$ indicate that the adsorption of the inhibitor (DAS extract) is an endothermic process representing that the dissolution of aluminum metal is slow in the presence of DAS extract constituents. The obtained $\Delta S_{\text {ads }}^{o}$ values are positive, which specify the increase of disorder owing to the adsorption of DAS extract constituents on an aluminum metal surface by desorption of more water molecules. This leads to an increase in adsorption entropy.

Heat of adsorption $\left(Q_{\mathrm{ads}}\right)$ was quantified from the surface coverage $(\theta)$ by plotting $\log (\theta / 1-\theta)$ against $1 / \mathrm{T}$. Slope values obtained from this plot was equivalent to $-\mathrm{Q} /$ 2.303R to which $Q_{\text {ads }}$ for different inhibitor concentrations can be evaluated. From Table 5 and Fig. 8, it can be concluded that, in all cases, the $\mathrm{Q}_{\mathrm{ads}}$ values are negative, indicating the adsorption of the DAS extract on aluminum surface is exothermic with releasing the more quantity of heat.

\subsection{Electrochemical Measurements}

\subsubsection{Tafel Plot (Potentiodynamic Polarization) Studies}

The kinetics of the cathodic and anodic corrosion reaction occurring at aluminum electrodes in $0.5 \mathrm{M} \mathrm{HCl}$ solution without and with different inhibitor concentration (DAS extract) were studied through the Tafel plot measurements by its current-potential data (Fig. 9). Parameters including

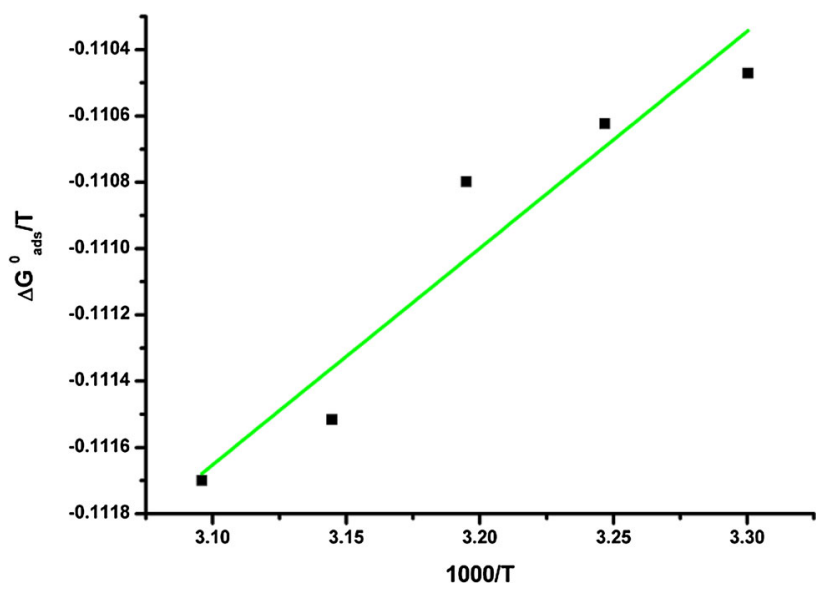

Fig. 7 Relationship between $\Delta \mathrm{G}_{\mathrm{ads}}^{\mathrm{o}}$ versus $1000 / \mathrm{T}$ 
Table 4 Values

of thermodynamic parameters for the adsorption of the inhibitor in $0.5 \mathrm{M} \mathrm{HCl}$ on the aluminum at different temperatures

\begin{tabular}{lllll}
\hline Temperature $(\mathrm{K})$ & $\mathrm{K}_{\text {ads }}\left(\mathrm{L} \mathrm{g}^{-1}\right)$ & $\Delta G_{\text {ads }}^{\mathrm{o}}\left(\mathrm{kJ} \mathrm{mol}^{-1}\right)$ & $\Delta H_{\text {ads }}^{\mathrm{o}}\left(\mathrm{kJ} \mathrm{mol}^{-1}\right)$ & $\Delta S_{\text {ads }}^{\mathrm{o}}\left(\mathrm{J} \mathrm{mol}^{-1} \mathrm{~K}^{-1}\right)$ \\
\hline 303 & 588.269 & -33.472 & 6.54 & 132.055061 \\
308 & 599.125 & -34.071 & 6.54 & 131.856716 \\
313 & 611.882 & -34.679 & 6.54 & 131.692726 \\
318 & 667.066 & -35.462 & 6.54 & 132.082236 \\
323 & 681.942 & -36.078 & 6.54 & 131.947270 \\
\hline
\end{tabular}

corrosion current density $\left(i_{\text {corr }}\right)$, cathodic $(\beta c)$ and anodic $(\beta a)$ Tafel slopes, and corrosion potential $\left(E_{\text {corr }}\right)$ values were generated from the software installed in the instrument $(\mathrm{CH}$ instrument). The corrosion current density values were used to evaluate the polarization resistance $\left(R_{\mathrm{p}}\right)$ values with the help of Stern-Geary equation [44]

$R_{\mathrm{p}}=\frac{\beta_{\mathrm{a}} \times \beta_{\mathrm{c}}}{2.303 \times\left[\beta_{\mathrm{a}}+\beta_{\mathrm{c}}\right] \times i_{\text {corr }}}$,

the rate of corrosion (mil/year) was determined from the following equation

Corrosion rate $=\frac{0.13 \times i_{\text {corr }} \times \text { E.W }}{\text { nd }}$,

where E.W = equivalent weight of the aluminum $(\mathrm{g})$, $d=$ density of aluminum $\left(\mathrm{g} / \mathrm{cm}^{3}\right), n=$ number of electrons, $i_{\text {corr }}=$ corrosion current density $(\mu \mathrm{A}), 0.13=$ metric and time conversion factor.

The percentage protection efficiency $\left(\eta_{\mathrm{p}}\right)$ at different concentration of DAS extract be evaluated from $i_{\text {corr }}$ values using the following equation

$\eta_{\mathrm{p}}=\left[1-\frac{i_{\text {corr }}}{i_{\text {corr }}}\right] \times 100$

where $i_{\text {corr }}$ and $i_{\text {corr }}$ are the current densities with and without inhibitor, respectively.

Kinetic parameters derived from Tafel plots are shortened in Table 6. It is evident from the table that corrosion current $\left(i_{\text {corr }}\right)$ values decreases rapidly with increment in the inhibitor concentration (DAS extract). The decreasing in the $i_{\text {corr }}$ values indicates the achievement of the suppression corrosion rate of aluminum metal in examining medium. $R_{\mathrm{p}}$ values enhanced in the presence of the inhibitor (DAS extract) compared with unprotected test solution indicating that high degree of protection to the aluminum metal surface by inhibitor molecules. As a result, the protection efficiency increases gradually and aluminum corrosion rate (mil/year) values reduced more rapidly with DAS extract concentration and the highest percentage protection efficiency (the lowest $i_{\text {corr }}$ value) is attained at the maximum concentration of the corrosion inhibitor (30 g/L of DAS extract). According to Ansari et al. [45] (1) if the displacement in corrosion potential $\left(E_{\text {corr }}\right)$ value is $>85 \mathrm{mv}$, the inhibitor acts as an anodic or
Table 5 Values of $Q$ ads at different concentrations of inhibitor (DAS extract)

\begin{tabular}{ll}
\hline Concentration $\left(\mathrm{g} \mathrm{L}^{-1}\right)$ & $Q_{\mathrm{ads}}(\mathrm{kJ} / \mathrm{mol})$ \\
\hline 5 & -15.188 \\
10 & -22.101 \\
20 & -32.711 \\
30 & -53.042 \\
\hline
\end{tabular}

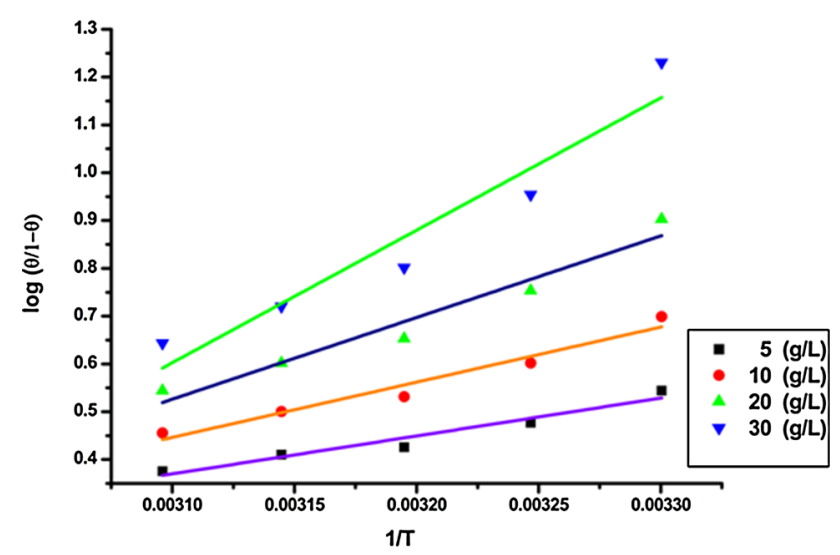

Fig. 8 Plot of $\log [\theta / 1-\theta]$ against $1 / \mathrm{T}$

cathodic type. (2) if displacement in corrosion potential ( $E_{\text {corr }}$ ) value is $<85 \mathrm{mv}$, the inhibitor can be seen as mixed type. In the present case, the maximum shift in $E_{\text {corr }}$ was 20 mv which indicates the mixed nature of the inhibitor (DAS extract). In addition, the marginal variation in the values of anodic and cathodic Tafel slopes further supported the mixed inhibition of DAS extract molecules on aluminum surface and impeded by merely blocking the aluminum metal surface with no varying the cathodic and anodic reaction mechanisms [46].

\subsubsection{AC Impedance Spectroscopy}

The impedance technique was applied to investigate the capacitive and resistive behavior of the electrode-acid interface. The corrosion behavior of electrode (aluminum) 


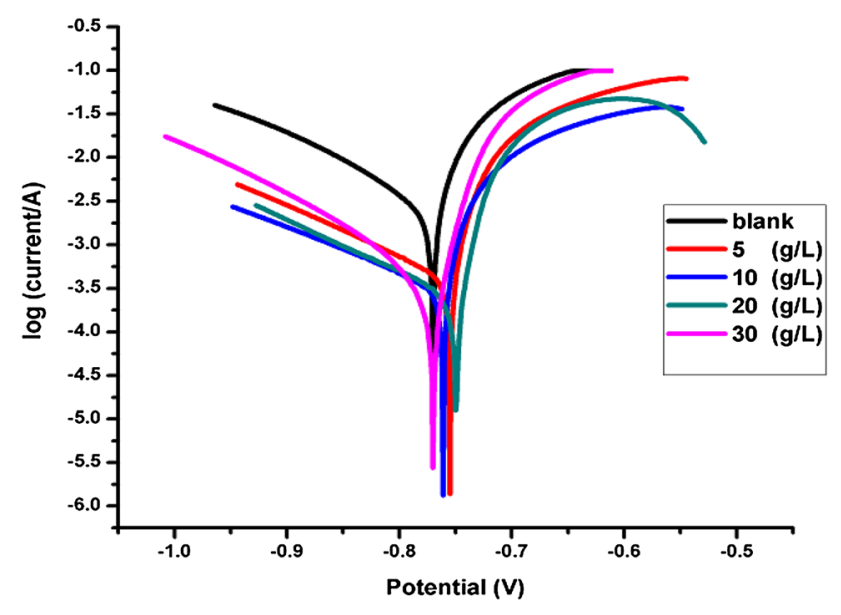

Fig. 9 Tafel plots for aluminum in $0.5 \mathrm{M} \mathrm{HCl}$ at various inhibitor concentrations

in acid media without and with that of DAS extract of different concentrations was analyzed through this technique. Nyquist curves are shown in Fig. 10.

Nyquist curves are analyzed with ZSimpwin 3.20 Program for data acquisition and analysis, this program provides good information about electrical circuit. An electrical circuit that fitted the finest impedance records is depicted in Fig. 11. As a result, the charge transfer resistance $\left(R_{\mathrm{ct}}\right)$, Chi-squared value $\left(\chi^{2}\right)$, frequency $\left(f_{\max }\right)$, constant phase element $(Q), \mathrm{CPE}$ exponent $(n)$, and double layer capacitance $\left(C_{\mathrm{dl}}\right)$ were determined. The percentage of protection efficiency $\left(\eta_{\mathrm{z}}\right)$ for each DAS extract concentration can be calculated from charge transfer resistance values according to the equation

$\eta_{\mathrm{z}}=\frac{R_{\mathrm{ct}(\mathrm{inh})}-R_{\mathrm{ct}}}{R_{\mathrm{ct}(\mathrm{inh})}} \times 100$

where $R_{\mathrm{ct}}$ and $R_{\mathrm{ct}(\mathrm{inh})}$ are the charge transfer resistance in unprotected and protected test solutions respectively.

The obtained and calculated electrical parameters are tabulated in Table 7. It is evident from the table that the $\mathrm{R}_{\mathrm{ct}}$ values significantly varied with the concentrations of the DAS extract demonstrating a charge transfer process principally controlling the aluminum corrosion. On the contrary, double layer capacitance $\left(C_{\mathrm{dl}}\right)$ and constant phase element $(Q)$ values decreased upon the addition of the DAS extract, suggesting that DAS extract molecules may condense the capacitance by means of enhancing the double film width as stated by the Helmholtz model, which reduces direct contact of aluminum metal with an acid solution. In the present work, the $\mathrm{n}$ values lies in the range of 1-0.9482 can be attributed to the adsorption of DAS extract molecules on the most active aluminum sites and superior surface heterogeneity. The relaxation time $(\tau)$ is the short period essential for attaining the charge distribution to an equilibrium which is specified through the following relation:

$\tau=C_{\mathrm{dl}} \times R_{\mathrm{ct}}$,

the adsorption of inhibitor wants some period to achieve equilibrium state, which is extremely petite as shown in Table 7 . The relaxation time amplified with enhancement in inhibitor concentration representing that the increase in adsorption constituents of DAS extract on the surface of aluminum which successfully reduced the area of electrode in corrosive atmosphere. The quality of fitting to the electrical equivalent circuit was judged by the $\chi^{2}$ values. The obtained $\chi^{2}$ values $(0.03898-0.00134)$ in the table indicate a good fit to the proposed circuit [47-56]. Percentage inhibition efficiencies values obtained from impedance studies, show the same trend as those obtained from Tafel plot and weight loss measurements.

\subsection{FT-IR Analysis}

The recorded IR spectrum (Fig. 12) of DAS extract showed a strong and broad band around $3183 \mathrm{~cm}^{-1}$ shows the presence of a monomeric hydroxyl group, and the presence of a carbonyl group is clearly manifested in the region of $1608 \mathrm{~cm}^{-1}$. Further, the absorption bands noticed at 2928 and $1280 \mathrm{~cm}^{-1}$ correspond to $\mathrm{C}-\mathrm{H}$ stretching vibrations. The band at $1063 \mathrm{~cm}^{-1}$ is assigned to $\mathrm{C}-\mathrm{O}$ group. The vibrating frequency of an $\mathrm{O}-\mathrm{C}=\mathrm{O}$ group can be confirmed by band at $2367 \mathrm{~cm}^{-1}$.

Table 6 Tafel parameters

\begin{tabular}{llllllr}
\hline $\begin{array}{l}\text { Concentration } \\
\left(\mathrm{g} \mathrm{L}^{-1}\right)\end{array}$ & $\begin{array}{l}\mathrm{E}_{\text {corr }} \\
(\mathrm{mV})\end{array}$ & $i_{\text {corr }} \times 10^{-3}(\mathrm{~A})$ & Corrosion rate $(\mathrm{mil} / \mathrm{year})$ & $\begin{array}{l}\beta \mathrm{c} \\
\left(\mathrm{V} \mathrm{dec}{ }^{-1}\right)\end{array}$ & $\beta \mathrm{a}\left(\mathrm{V} \mathrm{dec}{ }^{-1}\right)$ & $\begin{array}{l}\text { Linear polarization } \\
(R)(\Omega)\end{array}$ \\
\hline Blank & -770 & 8.916 & 3860.958 & 6.679 & 6.031 & 154.344 \\
5 & -755 & 2.106 & 911.976 & 5.924 & 6.561 & 641.865 \\
10 & -761 & 1.723 & 746.122 & 5.221 & 6.205 & 714.532 \\
20 & -750 & 1.073 & 464.648 & 5.751 & 6.187 & 1206.141 \\
30 & -770 & 0.703 & 304.684 & 7.593 & 8.288 & 2445.487 \\
\hline
\end{tabular}




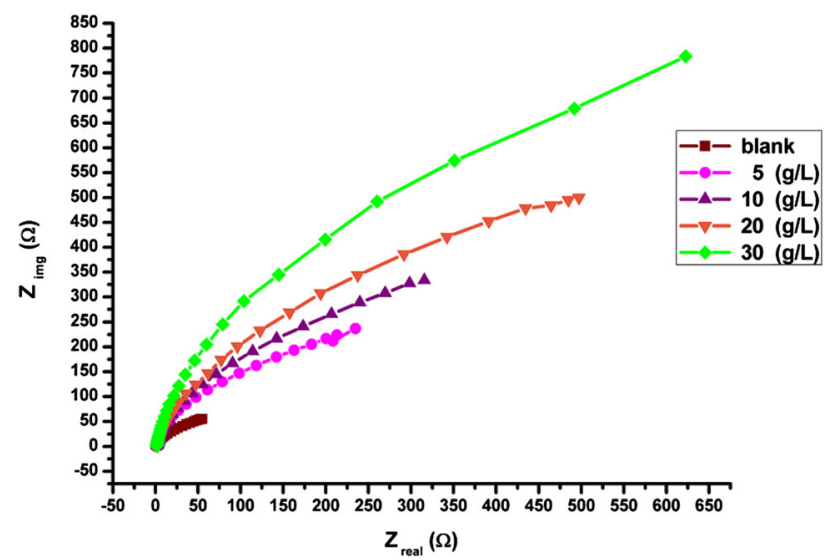

Fig. 10 Nyquist plots for aluminum in $0.5 \mathrm{M} \mathrm{HCl}$ in the absence and presence of DAS extract of different concentrations

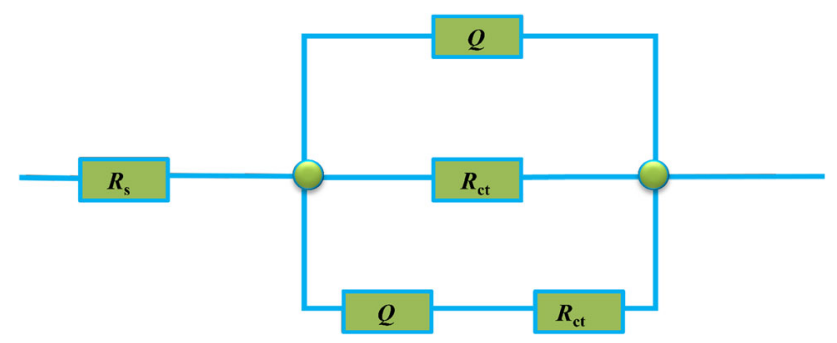

Fig. 11 Electrical equivalent circuit of $\mathrm{R}[\mathrm{QR}(\mathrm{QR})]$ model. Where $R_{\mathrm{S}}$ resistance of electrolyte in bulk, $R_{\mathrm{ct}}$ charge transfer resistance at the metal surface and $Q$ constant phase element

\subsection{Surface Analysis}

\subsubsection{Atomic Force Microscopy (AFM) Technique}

The AFM Photographs were taken and observed in order to support our findings. The AFM photographs were obtained from the aluminum surface before and after immersion in $0.5 \mathrm{M} \mathrm{HCl}$ solution in the absence and presence of an optimum concentration $(30 \mathrm{~g} / \mathrm{L})$ of DAS extract are shown in Fig. 13a, b. Inspection of the figures reveals that there is severe damage with corrosion products and cavities on the aluminum surface in the absence of DAS extract when compared to the AFM image of the aluminum specimen in the presence of the DAS extract molecules. This showed that the DAS extract component molecules hinder the dissolution of aluminum by forming a tenacious layer over aluminum surface. From AFM photographs, the calculated average roughness $\left(S_{\mathrm{a}}\right)$ values for aluminum metal immersed in $0.5 \mathrm{M} \mathrm{HCl}$ solution without DAS extract and with the addition of $30 \mathrm{~g} / \mathrm{L}$ of DAS extract is 451.000 and $68.003 \mathrm{n}, \mathrm{m}$ respectively. From this, it is clear that the

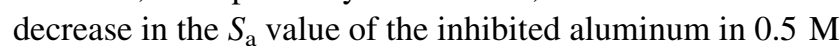
$\mathrm{HCl}$ media is ascribed to the formation of protective layer on aluminum surface, which confirms the inhibiting action of the DAS extract at aluminum/hydrochloric acid interface.

\subsubsection{Powder X-ray Diffraction Examination}

The DAS extract constituents and the DAS extract constituents adsorbed on the aluminum surface were scanned in the range of $0^{\circ}<2 \theta<80^{\circ}$ operated at $40 \mathrm{kV}$ and $15 \mathrm{~mA}$ at a wavelength of $1.5406 \AA$. Figure 14 shows the very high relative intensities of the peaks for the DAS extract, suggesting a mixture of crystallites in the form of powder. On adsorption of it on the surface of the aluminum metal, chemical reaction occurs by replacing the $\mathrm{H}^{+}$ions ( $\mathrm{Al}$ in acid media) present on the surface by DAS extract constituents. During this process, the peaks appeared for DAS extract is lost and hence it appeared like a continuous line as shown in Fig. 14 (as seen in

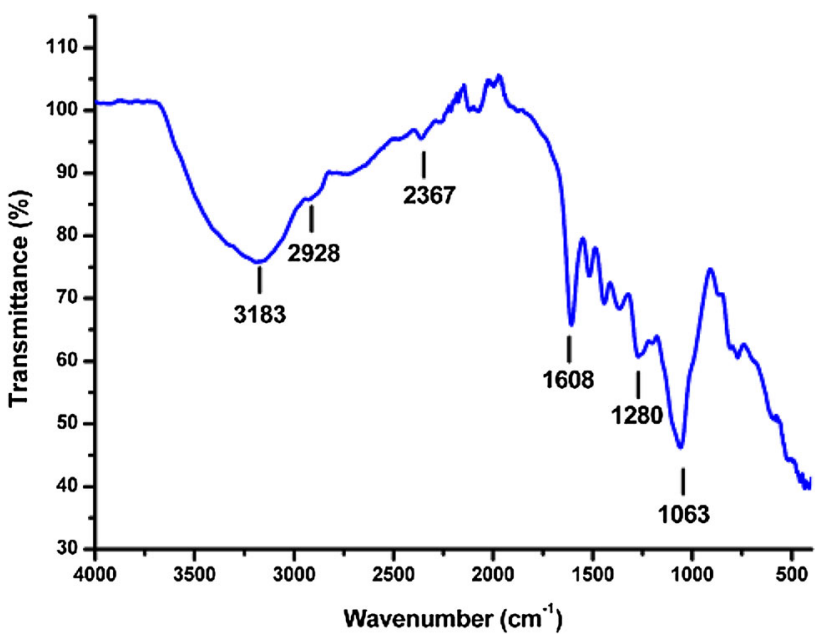

Fig. 12 FT-IR spectrum of DAS extract
Table 7 Electrochemical impedance parameters for the corrosion of aluminum in $0.5 \mathrm{M}$ $\mathrm{HCl}$ containing different concentrations of DAS extract

\begin{tabular}{llllllll}
\hline Concentration $\left(\mathrm{g} \mathrm{L}^{-1}\right)$ & $Q\left(\Omega^{-1} \mu \mathrm{s}^{\mathrm{n}}\right)$ & $n$ & $R_{\mathrm{ct}} \Omega$ & \multicolumn{1}{c}{$C_{\mathrm{dl}}(\mu \mathrm{F})$} & $\tau(s)$ & $\chi^{2}$ & $\eta_{\mathrm{z}}$ \\
\hline Blank & 126.6 & 1 & 55.94 & 291.355 & 0.016298 & 0.00147 & \\
5 & 121.3 & 1 & 228.7 & 153.362 & 0.035073 & 0.03898 & 75.540 \\
10 & 73.37 & 0.9885 & 375.3 & 137.310 & 0.051532 & 0.00134 & 85.094 \\
20 & 69.52 & 0.9482 & 534.8 & 79.611 & 0.042576 & 0.00233 & 89.540 \\
30 & 83.39 & 0.9893 & 1017 & 132.689 & 0.134945 & 0.00512 & 94.449 \\
\hline
\end{tabular}


Fig. 13 AFM 3D images of aluminum specimen. a Uninhibited system. b Inhibited system $\left(30 \mathrm{~g} \mathrm{~L}^{-1}\right.$ of DAS extract)
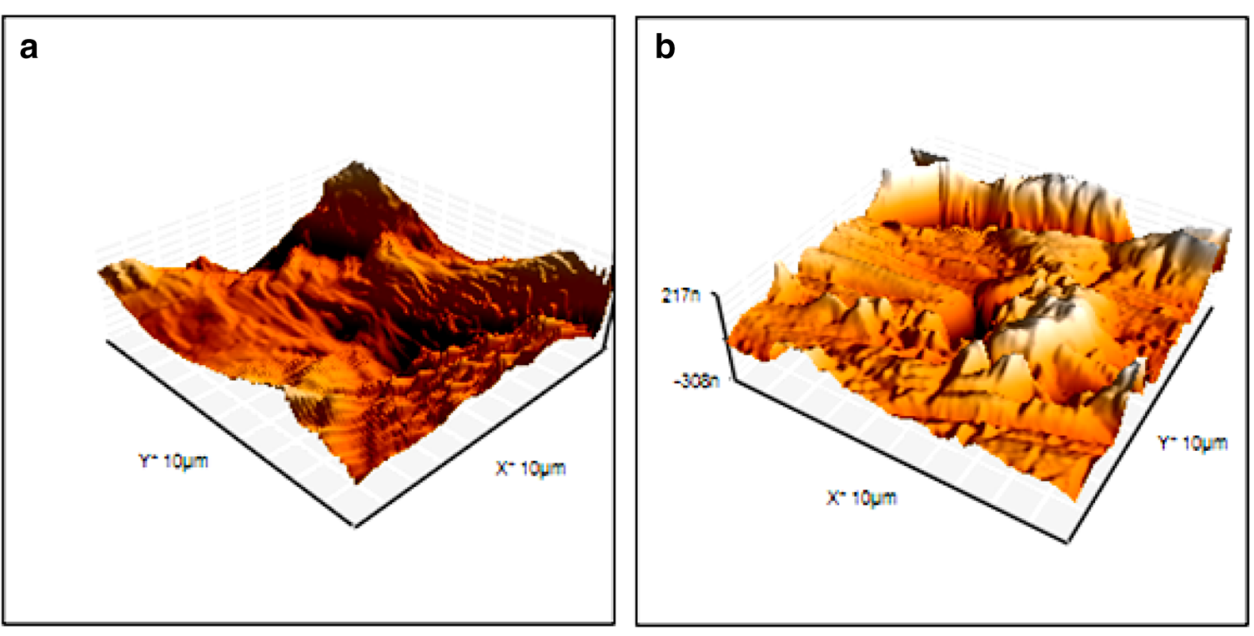

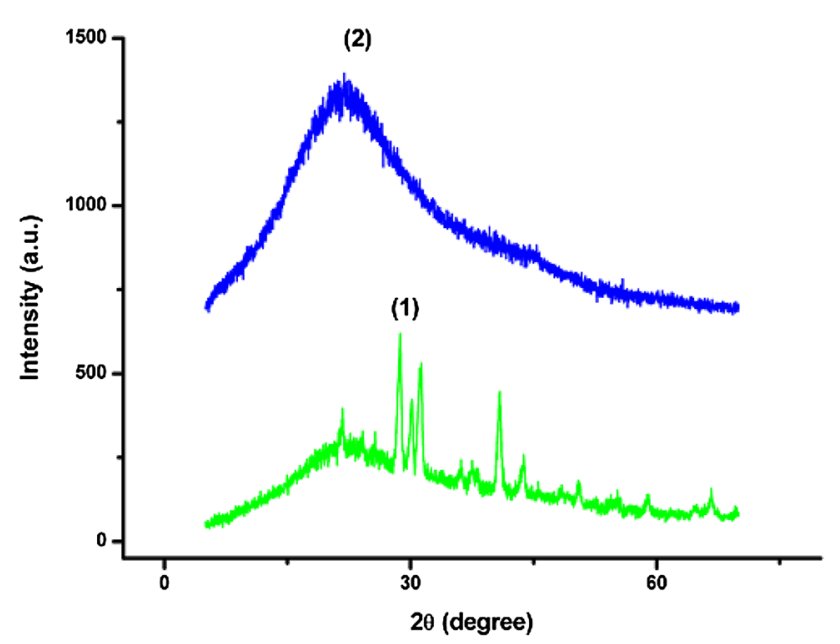

Fig. 14 Powder XRD pattern of DAS extract

Table 8 Crystallite sizes of DAS extract constituents

\begin{tabular}{lll}
\hline No. & $2 \theta$ (degree) & Particle size $(L)$ in \\
\hline 1 & 21.733 & 219 \\
2 & 22.19 & 10.8 \\
3 & 28.708 & 179 \\
4 & 30.167 & 204 \\
5 & 31.200 & 154 \\
6 & 40.807 & 163 \\
7 & 43.831 & 150 \\
8 & 58.99 & 196 \\
9 & 66.66 & 242 \\
\hline
\end{tabular}

Fig. 14 with a transformation from XRD with peaks (1) to XRD without peaks (2)). The crystalline size (L) obtained is as in Table 8 .

\section{Conclusions}

The present study showed that DAS extract could act as an efficacious green corrosion inhibitor for aluminum metal in hydrochloric acid environment. Results obtained from weight loss studies indicated that protection efficiencies were improved to increase in the DAS extract concentration and lowered with a rise in solution temperature. Adsorption of DAS extract molecules on the surface of the electrode in $0.5 \mathrm{M} \mathrm{HCl}$ solution obeyed the Langmuir adsorption isotherm model. Tafel plots suggested a mixed mode of action of the DAS extract molecules on aluminum surfaces. Alternating-current (AC) impedance spectroscopy results suggested that constituents of DAS extract were adsorbed on the electrode (aluminum) surface and modify the metal/acid solution interface. Protection efficiency values obtained from electrochemical and weight loss measurements were in good agreement. Further, AFM and powder XRD analysis also validates the results obtained from weight loss and electrochemical methods.

Acknowledgments The authors are grateful to Dr. B. E. Kumaraswamy of Kuvempu University for help and support.

\section{References}

1. Nestoridia M, Pletcher D (2008) The study of aluminium anodes for high power density Al/air batteries with brine electrolytes. J Power Sources 178:445-455

2. Sherif EM, Park SM (2006) Effects of 1, 4-naphthoquinone on aluminum corrosion in $0.50 \mathrm{M}$ sodium chloride solutions. Electrochim Acta 51:1313-1321

3. Lee EJ, Pyun SJ (1995) The effect of oxide chemistry on the passivity of aluminum surfaces. Corros Sci 37:157-168

4. Raghavendra N, Ishwara Bhat J (2016) Green approach to inhibition of corrosion of aluminum in $0.5 \mathrm{M} \mathrm{HCl}$ medium by tender arecanut seed extract: insight from gravimetric and electrochemical studies. Res Chem Intermed 42:6351-6372 
5. Diggle W, Downie TC, Goulding C (1970) The dissolution of porous oxide films on aluminium. Electrochim Acta 15:1079-1093

6. Pyun SI, Moon SM (1999) The inhibition mechanism of pitting corrosion of pure aluminum by nitrate and sulfate ions in neutral chloride solution. J Solid State Electrochem 3:331-336

7. Pyun SI, Lee WJ (2001) The effect of prior Cl-ion incorporation into native oxide film on pure aluminium in neutral chloride solution on pit initiation. Corros Sci 43:353-363

8. Eddy NO, Odoemelam SA, Odiongenyi AO (2009) Joint effect of halides and ethanol extract of Lasianthera africana on inhibition of corrosion of mild steel in $\mathrm{H}_{2} \mathrm{SO}_{4}$. J Appl Electrochem 39:849-857

9. Bahrami MJ, Hosseini SMA, Pilvar P (2010) Experimental and theoretical investigation of organic compounds as inhibitors for mild steel corrosion in sulfuric acid medium. Corros Sci 52:2793-2803

10. Binks PB, Fletcher PD, Salama IE (2011) Quantitative prediction of the reduction of corrosion inhibitor effectiveness due to parasitic adsorption onto a competitor surface. Langmuir 27:469-473

11. De Souza FS, Spinelli A (2009) Caffeic acid as a green corrosion inhibitor for mild steel. Corros Sci 51:642-649

12. Raja PB, Sethuraman MG (2008) Natural products as corrosion inhibitor for metals in corrosive media. Mater Lett 62:113-116

13. Fouda AS, Mohamed FSH, El-Sherbeni MW (2016) Corrosion inhibition of aluminum-silicon alloy in hydrochloric acid solutions using carbamidic thioanhydride derivatives. J Bio Tribo Corros 2:2-11

14. Lebrini M, Lagrenee M, Vezin H, Gengembre L, Bentiss F (2005) Electrochemical and quantum chemical studies of new thiadiazole derivatives adsorption on mild steel in normal hydrochloric acid medium. Corros Sci 47:485-505

15. Oguzie EE (2007) Corrosion inhibition of aluminium in acidic and alkaline media by Sansevieria trifasciata extract. Corros Sci 49:1527-1539

16. Subramanyam NC, Sheshadri BS, Mayanna SM (1993) Thiourea and substituted thioureas as corrosion inhibitors for aluminium in sodium nitrite solution. Corros Sci 34:563-571

17. Abd El Haleem SM, Abd El Wanees S, Abd El Aal EE, Farouk A (2013) Factors affecting the corrosion behaviour of aluminium in acid solutions. I. Nitrogen and/or sulphur-containing organic compounds as corrosion inhibitors for $\mathrm{Al}$ in $\mathrm{HCl}$ solutions. Corros Sci 68:1-13

18. Abiola OK, James AO (2010) The effects of aloe vera extract on corrosion and kinetics of corrosion process of zinc in $\mathrm{HCl}$ solution. Corros Sci 52:661-664

19. El-Etre AY (2003) Inhibition of aluminum corrosion using Opuntia extract. Corros Sci 45:2485-2495

20. Abiola OK, Otaigbe JOE (2009) The effects of Phyllanthus amarus extract on corrosion and kinetics of corrosion process of aluminum in alkaline solution. Corros Sci 51:2790-2793

21. Gunasekaran G, Chauhan LR (2004) Eco friendly inhibitor for corrosion inhibition of mild steel in phosphoric acid medium. Electrochim Acta 49:4387-4395

22. Muller B (2002) Corrosion inhibition of aluminium and zinc pigments by saccharides. Corros Sci 44:1583-1591

23. Wang CK, Lee WH (1996) Separation, characteristics, and biological activities of phenolics in Areca fruit. J Agric Food Chem 44:2014-2019

24. Wang CK, Lee WH, Peng CH (1997) Contents of phenolics and alkaloids in Areca catechu linn. during maturation. J Agric Food Chem 45:1185-1188

25. Hu CW, Chao MR (2012) Direct-acting DNA alkylating agents present in aqueous extracts of areca nut and its products. Chem Res Toxicol 25:2386-2392
26. Hamsar MN, Ismail S, Mordi MN, Ramanathan S, Mansor SM (2011) Antioxidant activity and the effect of different parts of Areca catechu extracts on glutathione-S-transferase activity in vitro. Free Rad Antioxid 1:28-33

27. Tsarev SG (1952) Synthetic arecoline. Veternariya 29:57-59

28. Nayar A (1997) The metals databook. Tata McGraw-Hill Publishing Ltd, New Delhi.

29. Tawancy HM, Ul-Hamid A, Abbas NM (2004) Practical engineering failure analysis. Marcel Dekker, New York, p 352

30. Cullity BD (1978) Elements of X-ray diffraction, 2nd edn. Addison-Wesley, Reading, p 102

31. Zhang X, Zheng Y, Wang X, Yan Y, Wei W (2014) Corrosion inhibition of N80 steel using novel diquaternary ammonium salts in $15 \%$ hydrochloric acid. Ind Eng Chem Res 53:14199-14207

32. Kamal C, Sethuraman M (2012) Caulerpin—a bis-indole alkaloid as a green inhibitor for the corrosion of mild steel in $1 \mathrm{M} \mathrm{HCl}$ solution from the marine alga Caulerpa racemosa. Ind Eng Chem Res 51:10399-10407

33. Li XH, Deng SD, Fu H, Li TH (2009) Adsorption and inhibition effect of 6-benzylaminopurine on cold rolled steel in $1.0 \mathrm{M} \mathrm{HCl}$. Electrochim Acta 54:4089-4098

34. Martinez S, Matikos-Hukovic M (2003) A nonlinear kinetic model introduced for the corrosion inhibitive properties of some organic inhibitors. J Appl Electrochem 33:1137-1142

35. Ostovari A, Hoseinieh SM, Peikari M, Shadizadeh SR, Hashemi SJ (2009) Corrosion inhibition of mild steel in $1 \mathrm{M} \mathrm{HCl}$ solution by henna extract: a comparative study of the inhibition by henna and its constituents (lawsone, gallic acid, $\alpha$-D-glucose and tannic acid). Corros Sci 5:1935-1949

36. Dandia A, Gupta SL, Singh P, Quraishi MA (2013) Ultrasoundassisted synthesis of pyrazolo[3,4-b]pyridines as potential corrosion inhibitors for mild steel in $1.0 \mathrm{M} \mathrm{HCl}$. ACS Sustain Chem Eng 1:1303-1310

37. Ahamad I, Prasad R, Quraishi MA (2010) Experimental and theoretical investigations of adsorption of fexofenadine at mild steel/hydrochloric acid interface as corrosion inhibitor. J Solid State Electrochem 14:2095-2105

38. Ahamad I, Prasad R, Quraishi MA (2010) Thermodynamic, electrochemical and quantum chemical investigation of some schiff bases as corrosion inhibitors for mild steel in hydrochloric acid solutions. Corros Sci 52:933-942

39. Obot IB, Obi-Egbedi NO (2011) Anti-corrosive properties of xanthone on mild steel corrosion in sulphuric acid: experimental and theoretical investigations. Curr Appl Phys 11:382-392

40. Langmuir I (1916) The constitution and fundamental properties of solids and liquids. Part 1. Solids. J Am Chem Soc 38:2221-2295

41. Zarrouk A, Hammouti B, Dafali A, Bentiss F, Oujda M (2013) Inhibitive properties and adsorption of purpald as a corrosion inhibitor for copper in nitric acid medium. Ind Eng Chem Res 52:2560-2568

42. Solomon MM, Umoren SA, IUdosoro II, Udoh AP (2010) Inhibitive and adsorption behaviour of carboxymethyl cellulose on mild steel corrosion in sulphuric acid solution. Corros Sci 52:1317-1325

43. Outirite M, Lagrenée M, Lebrini M, Traisnel M, Jama C, Vezin H, Bentiss F (2010) AC impedance, X-ray photoelectron spectroscopy and density functional theory studies of 3,5-bis $(n$-pyridyl)-1,2,4-oxadiazoles as efficient corrosion inhibitors for carbon steel surface in hydrochloric acid solution. Electrochim Acta 55:1670-1681

44. Stern M, Geary AL (1957) Electrochemical polarization I. A theoretical analysis of the shape of polarization curves. J Electrochem Soc 104:56-63

45. Ansari KR, Quraishi MA, Singh A (2014) Schiff's base of pyridyl substituted triazoles as new and effective corrosion inhibitors for mild steel in hydrochloric acid solution. Corros Sci 79:5-15 
46. Li W, He Q, Zhang S, Pei B, Hou B (2008) Some new triazole derivatives as inhibitors for mild steel corrosion in acidic medium. J Appl Electrochem 38:289-295

47. Pan YC, Wen Y, Xue L, Guo XU, Yang HF (2012) Adsorption behavior of methimazole monolayers on a copper surface and its corrosion inhibition. J Phys Chem C 116:3532-3538

48. Shubha HN, Venkatesha TV, Vathsala K, Pavitra MK, Punith Kumar MK (2013) Preparation of self assembled sodium oleate monolayer on mild steel and its corrosion inhibition behavior in saline water. ACS Appl Mater Interfaces 5:10738-10744

49. Olasunkanmi LO, Obot IB, Kabanda MM, Ebenso EE (2015) Some quinoxalin-6-yl derivatives as corrosion inhibitors for mild steel in hydrochloric acid: experimental and theoretical studies. J Phys Chem C 119:16004-16019

50. Bentiss F, Lebrini M, Vezin H, Chai F, Traisnel M, Lagrenee M (2009) Enhanced corrosion resistance of carbon steel in normal sulfuric acid medium by some macrocyclic polyether compounds containing a 1,3,4-thiadiazole moiety: AC impedance and computational studies. Corros Sci 51:2165-2173

51. Shiri HM, Ehsani A, Shayeh JS (2015) Electrochemical study of supercapacitor performance of polypyrrole ternary nanocomposite electrode by fast fourier transform continuous cyclic voltammetry. RSC Adv 5:91062-91068

52. Roy P, Maji T, Dey S, Sukul D (2015) Adsorption behaviour of gluten hydrolysate on mild steel in $1 \mathrm{M} \mathrm{HCl}$ and its role as a green corrosion inhibitor. RSC Adv 5:61170-61178

53. Alkhathlan HZ, Khan M, Abdullah MMS, AlMayouf AM, Yacine Badjah-Hadj-Ahmed A, Alothman ZA, Mousa AA (2015) Anticorrosive assay-guided isolation of active phytoconstituents from Anthemis pseudocotula extracts and a detailed study of their effects on the corrosion of mild steel in acidic media. RSC Adv 5:54283-54292

54. Gerengi H (2012) Anticorrosive properties of date palm (Phoenix dactylifera L.) fruit juice on 7075 type aluminum alloy in $3.5 \%$ $\mathrm{NaCl}$ solution. Ind Eng Chem Res 51:12835-12843

55. Bozorg M, Shahrabi Farahani T, Neshati J, Chaghazardi Z, Mohammadi Ziarani G (2014) Myrtus communis as green inhibitor of copper corrosion in sulfuric acid. Ind Eng Chem Res 53:4295-4303

56. Kumar SH, Karthikeyan S (2013) Torsemide and furosemide as green inhibitors for the corrosion of mild steel in hydrochloric acid medium. Ind Eng Chem Res 52:7457-7469 